\title{
Family violence and its 'adversity package': a community survey of family violence and adverse mental outcomes among young people
}

\author{
Tawanchai Jirapramukpitak • T. Harpham • \\ M. Prince
}

Received: 17 August 2009/Accepted: 7 June 2010/Published online: 20 June 2010

(C) The Author(s) 2010. This article is published with open access at Springerlink.com

\begin{abstract}
Background Limited research has examined the relationship between common forms of family violence and their impacts. We (1) examine the co-occurrence of exposure to domestic violence (EDV) and physical abuse (PA) in childhood and their relations to intimate partner violence (IPV) in adulthood among the young Thai people, and (2) describe their associations with common adverse mental outcomes.

Methods A population-based cross-sectional survey was conducted in a community in Bangkok on a representative sample of 1,052 young residents, aged 16-25 years. Measurements were as follows: (1) exposures-the Conflict Tactics Scales were used to assess EDV and PA in childhood and IPV in adulthood, and (2) outcomes-common mental disorder and suicidal ideation were assessed with Clinical Interview Schedule-Revised, illicit drug use with Diagnostic Interview Schedule, and problem drinking with Alcohol Use Disorder Identification Test.

Results Those who reported EDV and PA were highly likely to report IPV (OR 9.3, 95\% CI 4.4-19.4). In general, strong associations were found between exposure to each

T. Jirapramukpitak $(\bowtie)$

Department of Psychiatry, Faculty of Medicine,

Thammasat University, Paholyothin Road, Klong Luang,

Pathumthani 12120, Thailand

e-mail: tawanchaij@gmail.com

T. Harpham

Department of Urban, Environment and Leisure Studies, London South Bank University, 103 Borough Road,

London SE1 0AA, UK

T. Jirapramukpitak $\cdot$ M. Prince

Section of Epidemiology, Institute of Psychiatry,

DeCrespigny Park, London SE5 8AF, UK
\end{abstract}

form of the violent experiences and all the adverse outcomes (adjusted odds ratios ranged from 1.7 to 5.7). Those who had been exposed to the three types of violence, compared to none, were most likely to report all the adverse outcomes (odds ratios ranged from 4.3 to 17.3). Conclusion Those who had experienced both kinds of the childhood violence were particularly likely to get revictimised later in their life. A dose-response relationship was observed between the extent of exposure to violence and the adverse outcomes. There is a need to identify and prevent these experiences and their impact on children and young people.

Keywords Child abuse - Intimate partner violence . Mental disorders · Youth · Thailand

\section{Introduction}

Common forms of family violence, such as domestic violence and child physical abuse, have been highlighted as both a global human rights and a public health concern [1, 2]. Despite the growing body of research in the field, it has tended to focus on either domestic violence or child abuse, in spite of their potential for co-morbidity. They cannot be tackled effectively if one focuses on one form of violence, without taking into account of other related abusive experiences. For example, a review suggested that there was a high level of overlap between domestic violence and child physical abuse, ranging from 30 to $60 \%$ [3]. Children with physical abuse (PA) also tend to get re-victimised by a partner later in life [4]. However, much less is known about the co-occurrence between exposure to domestic violence (EDV) and PA in childhood and their relationships with intimate partner violence (IPV) in adulthood. 
Considering the potential adverse impacts of family violence, anxiety, depression, suicide, substance and alcohol use disorders are the most common mental health problems among young people in many parts of the world $[2,5,6]$. Considerable evidence is also available on the lifetime consequences of family violence among adults [7]. Nevertheless, relatively little is known about its current impact on mental health of young people. With a rapid rise in family problems and youth behavioural problems in many countries, a better understanding of the contribution of intra-familial violence to the development of such problems will be of potential relevance to public health policy and planning.

Population-based research on child maltreatment and domestic violence to date has come mainly from western countries [8-10]. Available data suggest that the prevalence of, e.g., child fatal abuse in low-to-middle income countries are two to three times higher than those in high income countries, and that Southeast Asia Region has one of the highest rates in the world [2]. In a similar fashion, evidence also suggests that the prevalence of IPV tends to be much higher in the developing world [11]. Previous studies of child abuse and domestic violence in Thailand and other Southeast Asian countries have been very few. A small community study in Bangkok found that $11.7 \%$ of people, aged 16-25, reported they had experienced PA of substantial degree in childhood [12]. In the Philippines, $26 \%$ of women, aged $15-49$, reported that they had been physically assaulted by a partner in their lifetime, while $20 \%$ of the married men in Thailand reported the use of violence against their spouse in the current relationships [13].

This report investigates the co-morbidity between the experience of domestic violence and PA in childhood and their relations to IPV in adulthood, and describes their associations with current adverse outcomes, namely common mental disorders (CMDs), suicidal ideation, illicit drug use and problem drinking, in a community sample of young Thai people in Bangkok.

\section{Methods}

The study employed a whole population catchment area cross-sectional survey design. A sample of 1,052 eligible residents, aged 16-25 years, living in a catchment area called Rangsit, was recruited. It is located adjacent to the north border of Bangkok and in recent years has been integrated into the metropolis. We first enumerated the catchment area population by knocking the doors of all households, identifying young people aged $16-25$ years. In the event that there was more than one eligible resident in a given household, we selected one at random to be interviewed using the Kish Grid method [14].
The selected individuals were interviewed by trained interviewers in their own homes during October 2003-May 2004. The main survey instruments consisted of two parts: an interviewer administered questionnaire, and a selfadministered questionnaire on violence exposure and history of illicit drug use. Participation in the study was voluntary and written informed consent was sought. The selfreport questionnaire was completed by the respondents in private and returned in a sealed envelope to the interviewer. This approach was used to ensure respondent confidentiality. All the participants were offered a list of organisations that specialised in mental health services.

Mental health outcomes

CMD was assessed by the structured, lay-administered Revised Clinical Interview Schedule (CIS-R) [15], which estimated prevalence for the 1 -week period prior to interview. The CIS-R has been used extensively in many countries such as Tanzania [16], Thailand [12], and the UK [17]. Those meeting the ICD-10 diagnostic criteria for nonpsychotic disorders or scoring 12 or above on the CIS-R were regarded as having a CMD.

Suicidal ideation was assessed with a question taken from the CIS-R. Suicidal thought was regarded as present, if the respondent responded positively to the question: 'In the past week, have you thought of killing yourself?'

Illicit drug use was assessed using an anonymous selfreport adapted from the substance use/dependence section of the Diagnostic Interview Schedule (DIS) [18]. A list of drug items was provided, including cannabis, amphetamines, opiates, cocaine, hallucinogens, ecstasy and solvents, which covered the majority of the illicit drugs used in Thailand and most parts of the world $[6,19]$. Those who reported the use of any of the listed substance within the previous year were regarded as having a history of illicit drug use.

Problem drinking was assessed using the Alcohol Use Disorder Identification Test (AUDIT), a structured and standardised instrument, which provides valid and reliable detection of hazardous and harmful use of alcohol in a general population [20].

Exposure variables and potential confounders

Socio-demographic factors included: (1) respondents' age and gender, (2) head of household's years of education, and (3) household assets-ownership of items including refrigerator, computer, air conditioner, microwave, washing machine and car. Previous studies in developing countries have argued for and used household asset indices as proxies to measure household socio-economic status, rather than monetary measures [21]. 
The three forms of family violence were screened with anonymous self-administered questionnaires. These covered EDV, child physical abuse and IPV. Questions on the three types of violence were slightly modified from the Conflict Tactic Scale (CTS) [22]. The age of 16 or under was agreed as the critical childhood period of enquiry regarding childhood EDV and PA. The items used to define the violent experiences were as follows.

Exposure to domestic violence (EDV): "How often did your father (or step father) or mother's boyfriend do any of these things to your mother (or stepmother) (1) push, grab, slap, or throw something at her? (2) kick, bite, hit her with a fist, or hit her with something hard? (3) repeatedly hit her over at least a few minutes? (4) threaten her with a knife or gun, or use a knife or gun to hurt her?"

Physical abuse (PA): "How often did a parent or other adults in the household (1) actually push, grab, or shove you? (2) throw something at you? (3) slap you on the face, ear or head? (4) hit you so hard that you had marks or bruises? (5) kick, punch, or hit you with a fist? (6) threaten to hurt you or actually hurt you with a gun, knife, or other weapon?"

Intimate partner violence (IPV): For those who are having a spouse, sexual partner, or lover, "how often did your spouse, sexual partner or lover (1) push, grab, slap, or throw something at you? (2) kick, bite, hit you with a fist or hit you with something hard? (3) repeatedly hit you over least a few minutes? (4) threaten you with a knife or gun, or use a knife or gun to hurt you?"

Exposure to each form of violence was regarded as present if the respondent reported they had sometimes, often or very often experienced one or more of the events within the category concerned (before the age of 16 in the cases of EDV and PA and any time in the current relationship in the case of IPV). However, those who had been subjected to particular acts of severe or very severe degree (item 4 of EDV, item 6 of PA, and item 4 of IPV) only once or more times were regarded as experiencing that type of violence.

\section{Data analysis}

Statistical analyses were performed with STATA version 10.0. In bivariate analysis, we estimated the odds ratios for the associations between the three forms of family violence and between the violent experiences and the adverse mental outcomes. In multivariate analysis (logistic regression), we estimated the independent associations of each of the three forms of violence with the adverse outcomes having controlled for the potential confounding effects of other variables including age, gender, head of household's education and household asset. All the bivariate and multivariate analyses were weighted back, using STATA svy commands, to take into account the total number of eligible young people in a given household.

\section{Results}

All the addresses of the selected catchment districts were approached to identify private households with at least one person aged 16-25. A total of 1,080 households contained at least one eligible resident. Of those eligible persons selected $(n=1,080), 2.3 \%$ could not be contacted $(n=25)$ and a further $0.3 \%$ refused to participate $(n=3)$, leaving 1,052 successfully completed interviews. The overall proportion responding was, therefore, $97.4 \%$

EDV was reported in $11.6 \%$, PA $16.7 \%$ and IPV $6.2 \%$ (9.2\% among ever-partnered participants, $n=702$ ). There were no differences in prevalence of abusive experiences of any kind between men and women. Those who reported EDV were more likely to report PA (OR 5.6, 95\% CI 3.4-9.1). Those who reported either EDV or PA were more likely to report IPV, with odds ratios of 4.5 (95\% CI 2.4-8.4) and 3.3 (95\% CI 1.9-6.0), respectively. Those reporting both exposure to EDV and PA were most likely to have experienced IPV (OR 9.3, 95\% CI 4.4-19.4).

Those reporting experiencing any one kind of violence were generally more likely to report the three outcomes (Table 1). The impact of having suffered more than one form of violence was also examined. For each outcome, there was a trend towards higher risk associated with multiple as opposed to single forms of violence. Tests for trend were significant for all the outcomes, namely CMD $(F=13.14, p=0.0003)$, suicidal thought $(F=13.14$, $p=0.0003)$, illicit drug use $(F=31.3, p<0.0001)$, and problem drinking $(F=21.56, p<0.0001)$.

The factors identified as being associated with or potentially associated with increased rates of one or more forms of violence were examined for their direct association with the adverse outcome variables to identify potential for confounding (Table 2). Being older was associated with problem drinking. Females tended to be suicidal, and were significantly less likely to have histories of illicit drug use and problem drinking. Fewer assets were associated with illicit drug use and problem drinking. Low education for the head of household was associated with history of illicit drug use. Overall, each of the abusive experiences was associated with all the adverse outcomes, with adjusted odds ratios of 1.7 or above. The associations were not substantially attenuated by the potential confounders. 
Table 1 Adverse mental outcomes by type and number of violence

\begin{tabular}{|c|c|c|c|c|c|c|c|c|c|}
\hline & \multirow{2}{*}{$\begin{array}{l}\text { Number of } \\
\text { participants }\end{array}$} & \multicolumn{2}{|l|}{ CMD } & \multicolumn{2}{|c|}{ Suicidal thought } & \multicolumn{2}{|l|}{ Illicit drugs } & \multicolumn{2}{|c|}{ Problem drinking } \\
\hline & & Prevalence & OR & Prevalence & OR & Prevalence & OR & Prevalence & OR \\
\hline \multicolumn{10}{|c|}{ Type of violence } \\
\hline \multicolumn{10}{|l|}{ EDV } \\
\hline No & 934 & 10.4 & & 0.8 & & 9 & & 22.5 & \\
\hline Yes & 118 & 19.2 & $2.0(1.2-3.5)$ & 1.7 & $2.1(0.4-11.2)$ & 25 & $3.4(1.7-6.6)$ & 37.8 & $2.1(1.2-3.5)$ \\
\hline \multicolumn{10}{|l|}{ PA } \\
\hline No & 880 & 10.0 & & 0.6 & & 9.3 & & 22.4 & \\
\hline Yes & 172 & 18.5 & $2.0(1.2-3.3)$ & 2.2 & $3.8(0.9-15.4)$ & 18.8 & $2.3(1.3-3.9)$ & 33.6 & $1.8(1.2-2.6)$ \\
\hline \multicolumn{10}{|l|}{ IPV } \\
\hline No & 990 & 10.9 & & 0.65 & & 9.6 & & 22.6 & \\
\hline Yes & 62 & 18.8 & $1.9(0.9-3.8)$ & 3.96 & $6.3(1.2-31.6)$ & 30.7 & $4.2(2.2-8.1)$ & 49.5 & $3.4(1.9-5.9)$ \\
\hline \multicolumn{10}{|c|}{ No. of types of violence } \\
\hline None & 788 & 9.3 & 1 & 0.5 & 1 & 7.0 & 1 & 20.1 & 1 \\
\hline 1 form & 192 & 15.9 & $1.8(1.1-3.1)$ & 1.6 & $3.1(0.6-15.3)$ & 21.5 & $3.6(2.0-6.6)$ & 34.0 & $2.0(1.3-3.1)$ \\
\hline 2 forms & 56 & 18.3 & $2.2(1.0-4.5)$ & 1.2 & $2.5(0.3-23.1)$ & 14.6 & $2.3(0.9-6.1)$ & 39.0 & $2.5(1.4-4.7)$ \\
\hline 3 forms & 16 & 32.0 & $4.6(1.4-14.5)$ & 8.0 & $17.3(1.8-170.3)$ & 48.0 & $12.3(4.1-37.0)$ & 52.0 & $4.3(1.5-12.7)$ \\
\hline
\end{tabular}

Table 2 Odds ratios for the associations between the three forms of violence and the adverse outcomes, adjusting for age, gender, head of household's education and asset index

\begin{tabular}{llccc}
\hline Characteristics & \multicolumn{2}{l}{ Adjusted odds ratios } & & \\
\cline { 2 - 5 } & CMD & Suicidal thought & Illicit drug use & Problem drinking \\
\hline Age $(<20$ years) & $0.9(0.6-1.4)$ & $1.7(0.4-8.0)$ & $0.8(0.5-1.4)$ & $2.0(1.4-2.9)$ \\
Sex (female) & $3.4(2.1-5.6)$ & $11.4(1.4-91.1)$ & $0.1(0.1-0.3)$ & $0.2(0.1-0.2)$ \\
Asset index (no asset) & $1.4(0.8-2.5)$ & $3.6(0.9-15.3)$ & $1.4(0.7-2.7)$ & $1.7(1.1-2.8)$ \\
Head of household's education & $1.1(0.7-1.7)$ & $0.3(0.1-1.2)$ & $2.2(1.3-3.7)$ & $1.0(0.7-1.5)$ \\
$\quad(\leq$ primary school education) & $2.3(1.3-4.1)$ & $2.73(0.5-14.6)$ & $2.8(1.4-5.5)$ & $1.8(1.0-3.0)$ \\
EDV & $2.2(1.4-3.6)$ & $4.0(0.9-17.5)$ & $2.0(1.1-3.5)$ & $1.7(1.1-2.7)$ \\
PA & $2.0(1.0-4.0)$ & $5.7(0.9-38.3)$ & $5.1(2.4-10.8)$ & $3.7(2.0-6.9)$ \\
IPV & & &
\end{tabular}

\section{Discussion}

Our data suggest that the two forms of childhood violence were highly co-morbid. Each form was associated with IPV but the EDV and PA together were highly predictive of IPV. A wealth of literature has established the coexistence between domestic violence and child abuse. Evidence of this comes from three types of study population. They are of either parents reporting their interspousal violence and abuse of their children [23, 24], or children reporting their abusive experiences and their exposure to interparental violence [25], or adults reporting their EDV and abuse in childhood [7]. Our findings also suggested that EDV and PA in childhood were each associated with re-victimisation in adult, which are in line with previous studies [26-28].
The fact that the risk of re-victimisation in adult life was highest when one had been exposed to both the forms of childhood violence indicates that the cumulative effect was a powerful one. This implies that an urgent assessment and intervention may be needed for children with a history of both exposures.

Several theories in the literature might help to explain our observations. Great overlap between EDV and PA seems to be in line with the family systems theory [29]. According to the theory, negative effect in one family relationship can spread to other family relationships. Families with husband-to-wife aggression may provide a negative background that pervades throughout the family. Our findings of the increased risk of IPV in later life support the intergeneration transmission of violence model, 
which holds that witnessing or experiencing family violence as a child leads to a greater use or tolerance of violence as an adult [30]. Exposure to violence between parents may teach youth that violence is an acceptable or effective means of resolving conflicts with partners. Child maltreatment may also be another pathway to the involvement in conflictual romantic relationships [31]. Attachment theory holds that individuals who have experienced maltreatment or attachment-related difficulties are more likely to report problems related to trust and closeness in subsequent relationships, and more likely to express hostility and anger towards others in a variety of ways [32].

In our study, a reported history of family violence was associated with a higher risk of current adverse mental outcomes in young adulthood. In general, no substantial differences in the extent of the impacts of EDV, PA and IPV were observed, perhaps IPV appeared to be much more strongly associated with suicidal thought, illicit drug use and problem drinking (ORs $\geq 3.4$ ). This may be due to one being more affected by the current or recent stress from IPV, compared to more remote events in childhood such as EDV and PA. For some outcomes, particularly suicidal thought, where positive associations with EDV and PA did not reach statistical significance, a plausible explanation is that low reporting of suicidal ideation decreases the statistical power of the analysis. Our findings also support the majority of the literature on non-specific mental health sequelae of various forms of family violence [8, 33-38].

As might be expected, those reporting more than one form of violence fared worse than those reporting a single type of violence. An overall trend for poorer mental health as the number of violence types increased was confirmed, implying that a dose-response relationship is present. Previous research has reported a higher negative impact of both EDV and PA on children's behaviours in combination when compared to experiencing either one of those [39].

Strengths of the current study include a relatively large community sample of young people of both genders, in which different types of family violence have been considered together, use of structured diagnostic interviews and a focus on current, rather than lifetime, adverse outcomes. We also obtained a high response rate from the eligible participants. However, a number of potential limitations need to be considered when interpreting the results of this study. This study was based on self-report, retrospective data, consequently, the relationships between those violent experiences and between the experiences and the adverse mental outcomes cannot be assumed to be causal. Illicit drug use or problem drinking, e.g., may lead to increased risks of IPV or the other way around. A study with a longitudinal design would be better able to establish the direction of causality.
Residual confounding also remained another potential limitation in our study. There were a number of other potentially relevant factors that were not assessed and adjusted (e.g., parental adjustment, exposure to childhood sexual abuse) and may have had a more substantial impact on the adjusted associations. They should, therefore, be regarded as upper limit estimators of the likely true associations. In addition, this is a study of those who gave a history of having been exposed to violence. This cannot be assumed to accurately reflect all of those in the study population who were truly exposed. Fortunately, the sample of young people in this study was probably less affected by recall errors than would have been the case for older people.

Family violence in childhood, whether through witnessing or directly experiencing it, may trigger a cycle of adversities, including re-victimisation, mental problems and other life difficulties. Rossman [40] adopted the term "adversity package" to describe the multiple stressors which can accumulate in the lives of young people exposed to such violence. Early detection and treatment for violence against young people and children therefore have the potential to interrupt and prevent the recurrences of violence and adverse psychological impact for both parents and children. Prevention strategies directed towards violence experienced by couples and/or their children should be integrated into public health and primary care planning. For example, when a woman is identified as a victim of IPV, an opportunity also exists to identify a maltreated child and vice versa. Mental problems commonly observed in young people, such as those reported in the present study, should alert health professionals to the possibility of violence in the family because of their potential association with history of such violence. Asking a potential victim directly should be done as part of routine clinical practice.

Although the consequences of family violence and its intergenerational transmission have been well studied, the next step should be to move beyond looking at simple relationships between these types of family violence in childhood and adulthood and between these abusive experiences and adverse outcomes. Longitudinal studies are needed to examine the biological, psychological and social mechanisms which may prevent or contribute to the development and course of subsequent violence and psychopathology.

\section{Conclusions}

EDV and PA in childhood, whether independently or particularly in combination, dramatically increase the risk of re-victimisation in adulthood among young Thai people. The population-based estimates of the adverse impact of 
single- and multi-category family violence on subsequent re-victimisation and mental health highlight the need for health professionals to be aware of these common experiences in order to identify, prevent the re-victimisation and minimise the impact.

Acknowledgments We thank the survey participants who openly shared their experience of violence, and the filed team members who took great care in interviewing youth on the sensitive topics of family violence and other private issues. The study was funded by a grant allocated from the Wellcome Trust Health Consequences of Population Change Programme with a postdoctoral fellowship (WT 069409).

Open Access This article is distributed under the terms of the Creative Commons Attribution Noncommercial License which permits any noncommercial use, distribution, and reproduction in any medium, provided the original author(s) and source are credited.

\section{References}

1. Pinheiro P (2006) Report of the independent expert for the United Nations study on violence against children. United Nations, Geneva

2. Krug EG, Dahlberg LL, Mercy JA, Zwi AB, Lozano R (eds) (2002) World report on violence and health. World Health Organization, Geneva

3. Edleson JL (1999) Children's witnessing of adult domestic violence. J Interpers Violence 14:839-870

4. Coid J, Petruckevitch A, Feder G, Chung W, Richardson J, Moorey S (2001) Relation between childhood sexual and physical abuse and risk of revictimisation in women: a cross-sectional survey. Lancet 358:450-454

5. Ayub M, Irfan M, Nasr T, Lutufullah M, Kingdon D, Naeem F (2009) Psychiatric morbidity and domestic violence: a survey of married women in Lahore. Soc Psychiatry Psychiatr Epidemiol 44:953-960

6. UNODC (2008) World drug report. United Nations Office on Drugs and Crime, Geneva

7. Dube SR, Anda RF, Felitti VJ, Edwards VJ, Williamson DF (2002) Exposure to abuse, neglect, and household dysfunction among adults who witnessed intimate partner violence as children: implications for health and social services. Violence Vict 17:3-17

8. Ellsberg M, Jansen HA, Heise L, Watts CH, Garcia-Moreno C (2008) Intimate partner violence and women's physical and mental health in the WHO multi-country study on women's health and domestic violence: an observational study. Lancet 371:1165-1172

9. Gilbert R, Widom CS, Browne K, Fergusson D, Webb E, Janson S (2009) Burden and consequences of child maltreatment in highincome countries. Lancet 373:68-81

10. Rosenman S, Rodgers B (2004) Childhood adversity in an Australian population. Soc Psychiatry Psychiatr Epidemiol 39:695-702

11. Garcia-Moreno C, Jansen HA, Ellsberg M, Heise L, Watts CH (2006) Prevalence of intimate partner violence: findings from the WHO multi-country study on women's health and domestic violence. Lancet 368:1260-1269

12. Jirapramukpitak T, Prince M, Harpham T (2005) The experience of abuse and mental health in the young Thai population. A preliminary survey. Soc Psychiatry Psychiatr Epidemiol 40:955-963

13. Heise L, Ellsberg M, Gottemoeller M (1999) Ending violence against women. John Hopkins University School of Public Health, Center for Communications Programs, Baltimore
14. Kish L (1965) Survey sampling. Wiley, London

15. Lewis G, Pelosi AJ, Araya R, Dunn G (1992) Measuring psychiatric disorder in the community: a standardized assessment for use by lay interviewers. Psychol Med 22:465-486

16. Ngoma M, Prince M, Mann A (2003) Common mental disorders among those attending primary health clinics and traditional healers in urban Tanzania. Br J Psychiatry 183:349-355

17. Jenkins R, Lewis G, Bebbington P, Brugha T, Farrell M, Gill B, Meltzer H (2003) The national psychiatric morbidity surveys of Great Britain-initial findings from the household survey. Int Rev Psychiatry 15:29-42

18. Robins L, Regier D (1991) Psychiatric disorders in America: the epidemiologic catchment area study. Free Press, New York

19. Wibulpolprasert S (ed) (2002) Thailand Health Profile 19992000, 1st edn. Printing Press, Express Transportation Organization, Nonthaburi

20. Saunders JB, Aasland OG, Babor TF, de la Fuente JR, Grant M (1993) Development of the Alcohol Use Disorders Identification Test (AUDIT): WHO Collaborative Project on early detection of persons with harmful alcohol consumption-II. Addiction 88: 791-804

21. Falkingham J, Namazie C (2002) Measuring health and poverty: a review of approaches to identifying the poor. Health Systems Resource Centre, London

22. Straus MA (1979) Measuring intrafamily conflict and violence: The Conflict Tactics (CT) Scales. J Marriage Fam 41:75-88

23. Hunter WM, Jain D, Sadowski LS, Sanhueza AI (2000) Risk factors for severe child discipline practices in rural India. J Pediatr Psychol 25:435-447

24. Margolin G, Gordis EB, Medina AM, Oliver PH (2003) The co-occurrence of husband-to-wife aggression family-of-origin aggression and child abuse potential in a community sample. J Interpers Violence 18:413-440

25. Klevens J, Bayon MC, Sierra M (2000) Risk factors and context of men who physically abuse in Bogota, Colombia. Child Abuse Negl 24:323-332

26. Ehrensaft MK, Cohen P, Brown J, Smailes E, Chen H, Johnson JG (2003) Intergenerational transmission of partner violence: a 20-year prospective study. J Consult Clin Psychol 71:741-753

27. Smith SM, Rosen KH, Middleton KA, Busch AL, Lundeberg K, Carlton RP (2000) The intergenerational transmission of spouse abuse: a meta-analysis. J Marriage Fam 62:640-654

28. Whitfield CL, Anda R, Dube S, Felitti V (2003) Violent childhood experiences and the risk of intimate partner violence in adults: assessment in a large health maintenance organization. J Interpers Violence 18:166-185

29. Larson RW, Almeida DM (1999) Emotional transmission in the daily lives of families: a new paradigm for studying family process. J Marriage Fam 61:5-20

30. Widom CS (1989) Does violence beget violence? A critical examination of the literature. Psychol Bull 106:3-28

31. Wolfe DA, Wekerle C, Reitzel-Jaffe D, Lefebvre L (1998) Factors associated with abusive relationships among maltreated and nonmaltreated youth. Dev Psychopathol 10:61-85

32. Zuravin S, McMillen C, DePanfilis D, Risley-Curtiss C (1996) The intergenerational cycle of child maltreatment: continuity versus discontinuity. J Interpers Violence 11:315-334

33. Johnson RM, Kotch JB, Catellier DJ, Winsor JR, Dufort V, Hunter W, Amaya-Jackson L (2002) Adverse behavioral and emotional outcomes from child abuse and witnessed violence. Child Maltreat 7:179-186

34. Briere J, Elliott D (2003) Prevalence and psychological sequelae of self-reported childhood physical and sexual abuse in a general population sample of men and women. Child Abuse Negl $27: 1205-1222$ 
35. Dube S, Anda R, Felitti V, Chapman D, Williamson D, Giles W (2001) Childhood abuse, household dysfunction, and the risk of attempted suicide throughout the life span: findings from the adverse childhood experiences study. JAMA 286:30893096

36. McHolm AE, MacMillan HL, Jamieson E (2003) The relationship between childhood physical abuse and suicidality among depressed women: results from a community sample. Am J Psychiatry 160:933-938

37. Widom CS, Schuck AM, White HR (2006) An examination of pathways from childhood victimization to violence: the role of early aggression and problematic alcohol use. Violence Vict 21:675-690

38. Simpson TL, Miller WR (2002) Concomitance between childhood sexual and physical abuse and substance use problems: a review. Clin Psychol Rev 22:27-77

39. Afifi TO, Enns MW, Cox BJ, Asmundson GJ, Stein MB, Sareen J (2008) Population attributable fractions of psychiatric disorders and suicide ideation and attempts associated with adverse childhood experiences. Am J Public Health 98:946-952

40. Rossman BBR (2000) Time heals all: how much and for whom? J Emot Abus 2:31-50 